\title{
Una crítica a la modernidad a partir de la 'inutilidad' del juego. El imperativo metanoético de Sloterdijk y la razón lúdica
}

\author{
A critique to modernity through the "useless character» of \\ play. Sloterdijk's metanoethical imperative and "ludic reason"
}

XAVIER GIMENO MONFORT \& FRANCISCO JAVIER LÓPEZ FRÍAS

colegio privado aula 3, Valencia \& Penn State University

Artículo recibido: 23 de diciembre de 2017

Solicitud de revisión: 9 de mayo de 2018

Artículo aceptado: 21 de mayo de 2018

Gimeno Monfort, Xavier \& López Frías, Francisco Javier (2018). Una crítica a la modernidad a partir de la "inutilidad" del juego. El imperativo metanoético de Sloterdijk y la razón lúdica. Recerca. Revista de Pensament i Anàlisi, 23, pp. 219-238.

Resumen

En este artículo se analiza el concepto de imperativo metanoético que Peter Sloterdijk presenta en jHas de cambiar tu vida! Nuestro objetivo es iluminar la naturaleza de lo que, en trabajos anteriores, hemos denominado -a raíz de la obra de Bernard Suits-, razón lúdica. Para ello, primero, expondremos y analizaremos el sentido del imperativo metanoético en Sloterdijk, así como los elementos principales de su razón ascética. Segundo, mostraremos cómo ambos son consecuencia del análisis ontológico de corte heideggeriano en la que Sloterdijk basa su propuesta de filosofía moral. Tercero, presentaremos en términos sloterdijkianos tanto el análisis ontológico de Suits, como el posible imperativo metanoético que se desprendería de su razón lúdica. Por último, centrándonos en el papel que Sloterdijk otorga a la figura del "ocioso", mostraremos las posibles conexiones entre Suits y Sloterdijk. Mostraremos la relación que existe entre los imperativos lúdicos y ascéticos donde, además, el acto «jugar» recibe un papel central en la «respuesta a la pregunta por el ser».

Palabras clave: filosofía del juego, deporte, hermenéutica crítica y ascesis.

Abstract

In this article, we analyze Peter Sloterdijk's concept of "metanoethical imperative" in You Must Change Your Life. Our goal is to shed light on what, by drawing on Bernard Suits, we call "ludic reason." To do so, we will present and examine in depth the meaning of Sloterdijk's metanoethical imperative, as well as the main features of his concept of "askesis." Second, we will argue that both concepts are the result of the Heideggerian ontologi- 
cal principles underlying Sloterdijk's moral philosophy. Third, we will provide a "Sloterdijkean" interpretation of Suits' account of games by focusing on the metanoethical imperative that could be derived from the notion of the ludic reason. To conclude, we will focus on the role that the figure of the "Good-for-Nothing" plays in Sloterdijk's account, showing connections between Suits' and Sloterdijk's approaches. We will argue that, in the philosophical approaches of both philosophers, the idea of game playing is closely tied to the "question on Being."

Keywords: philosophy of games, sport, critical hermeneutics and ascetic.

\section{SOBRE LA OPOSICIÓN ENTRE LA RAZÓN LÚDICA Y LA INSTRUMENTAL. UNA CRÍTICA A LA MODERNIDAD}

En anteriores trabajos hemos defendido una interpretación posmoder$\mathrm{na}^{1}$ del pensamiento del filósofo analítico angloamericano, Bernard Suits, el cual es conocido como uno de los fundadores de la filosofía del deporte por su obra The Grasshopper: games, life and utopia. En dicho trabajo, Suits presenta una definición de juego como «el intento voluntario de superar obstáculos innecesarios» (Suits, 1990: 41). Con ello, pretende revisar la posición de Ludwig Wittgenstein respecto al concepto de juego. Según esta, el juego es el ejemplo paradigmático de término que no se puede definir en función de elementos necesarios y suficientes, sino que, a lo sumo, se puede comprender en función de ciertos «aires de familia» entre las distintas actividades que denominamos como juego (Wittgenstein, 1988). Una vez refutada la posición wittgensteniana, y lejos de limitar su análisis del juego a lo puramente lingüístico-conceptual, Suits toma su definición para explorar la pregunta ontológica por el sentido de la vida, en concreto, sobre el sentido de la vida en sociedades modernas.

Como sabemos, para Aristóteles, la vida buena es aquella en la que el hombre se entrega a la contemplación dado que esta es, a fin de cuentas, la única actividad autotélica, es decir, valiosa por sí misma:

Tal parece ser eminentemente la felicidad, pues la elegimos siempre por ella misma y nunca por otra cosa [...] Parecerla que solo esta actividad se ama por sí misma, pues nada

1 Con posmoderna nos referimos al hecho de que, en lo que a literatura sobre Suits se refiere, la mayoría de las publicaciones giran en torno a dos ideas, a saber: el concepto de juego y su definición, así como el ideal de que la vida buena es aquella que implica jugar a juegos. No obstante, nadie ha presentado la filosofía de Suits como una crítica a la modernidad y su lógica, o más bien, razón instrumental. Al presentar a Suits como crítico de la racionalidad moderna, pues, le hemos concebido como un pensador posmoderno, pero moderno a la vez, ya que defendemos que su ideal de "vida lúdica» supone un modo de desarrollar y realizar nuestra autonomía. 
se saca de ella aparte de la contemplación, mientras que de las actividades prácticas obtenemos siempre algo, más o menos, aparte de la acción misma (Aristóteles, 1097b, 1017b).

En su intento por responder a la cuestión ontológica respecto al concepto de juego, Suits retoma el concepto aristotélico de actividad autotélica (Suits, 1974), pero revisa su contenido. Para él, la actividad autotélica por excelencia es la de jugar a juegos, y no la contemplación (Suits, 1990).

En un mundo como el nuestro, donde todo gira en torno al trabajo y el crecimiento material, identificar la actividad puramente autotélica con el jugar a juegos ha contribuido a una interpretación reductiva e, incluso, trivial de Suits (López Frías \& Gimeno, 2017; López Frías, 2017).A saber, según esta interpretación, la vida buena consiste en participar en aquello que hoy en día denominamos como juegos, por ejemplo, deportes, juegos de mesa, videojuegos, etc. Sin embargo, la tesis ontológico-existencial de Suits está muy lejos de esta interpretación, ya que no implica necesaria y únicamente el participar en las actividades que hoy denominamos como juegos. Para Suits, el concepto de jugar a juegos es mucho más amplio y esconde mucho más de lo que parece a simple vista (López Frías \& Gimeno, 2017).

Según Suits, como afirmamos anteriormente, el juego es toda aquella actividad que hace de la superación de obstáculos innecesarios su modo de ser. De este modo, lo que genera la posibilidad de jugar a un juego es la voluntaria limitación del uso de los medios más eficientes para alcanzar una meta. Al renunciar al uso de los medios más eficientes, los participantes en el juego se enfrentan voluntariamente a obstáculos añadidos que ponen a prueba sus habilidades. Este centrarse en la utilización de ciertas habilidades para superar limitaciones se convierte en el motivo principal de juego, en su elemento central. Lo importante del juego no es, pues, el logro del objetivo, sino el propio proceso de superación de obstáculos. Dicha aceptación voluntaria de obstáculos -solo para que la prueba sea posible-, es lo que Suits denomina «actitud lúdica» (Morgan, 2008; Suits, 1967).

La racionalidad moderna se define por su orientación instrumental, es decir, por el uso eficiente de medios para alcanzar fines. Jugar a juegos, por su parte, se fundamenta en un tipo de racionalidad muy distinto a la instrumental. La racionalidad del juego se basa en la ineficiencia o gratuidad, ya que nos empuja a participar solo en aquellas actividades que aceptamos de modo voluntario porque las deseamos por sí mismas, más allá de su valor o carácter instrumental. Este tipo de racionalidad, pues, es esencialmente crítica con la idea de razón moderna, ya que conduce a una actitud, en términos orteguianos, «jovial» $\mathrm{O}$ «vitalista». La razón lúdica nos invita a vivir la vida a través del constante -parafraseando a Kant-, "darnos a nosotros 
mismos nuestros propios obstáculos y entregarnos a su superación como modo de vida» (López Frías, 2017).

Los obstáculos que encontramos en nuestra vida, pues, no nos vienen determinados por necesidades o por otros agentes de modo heterónomo, sino que nos los autoimponemos de modo autónomo. En este sentido, Suits, a nuestro juicio, propone un modelo de razón lúdica moderno que potencia la autonomía humana, pero, a su vez, limita el poder controlador de la razón instrumental. Siguiendo esta lógica, afirma Suits, cualquier actividad puede ser considerada como un juego, con tal de que tomemos los obstáculos que nos presenta, así como las habilidades requeridas para superarlos, como lo puramente valioso de ellas.

Por ejemplo, un carpintero para el que la tarea de construir una casa es algo tedioso y pesado con lo que ganar un sueldo a fin de mes, no concibe el uso de sus habilidades para la carpintería como un fin en sí mismo, sino como medio para otro fin: un salario. Por el contrario, si ese mismo carpintero cambia su actitud y concibe la construcción de la casa como una actividad intrínsecamente valiosa que pone a prueba, por ejemplo, sus habilidades trabajando la madera, entonces podemos decir que el carpintero está jugando a un juego. El carpintero construye la casa solo porque quiere poner a prueba sus habilidades con la madera, no con una motivación instrumental (Suits, 1984).

Con esto, no queremos reducir la facticidad de la existencia humana, al hecho de que deberíamos solo interpretar la existencia como un reto en el que ponernos obstáculos voluntariamente; ni siquiera afirmamos que la vida sea solo un juego. Lo que afirmamos es más realista, a saber: que la racionalidad que atraviesa de arriba abajo la inmensa mayoría de las actividades humanas es, a la sazón, una racionalidad instrumental. Esta no atiende a otro principio valorativo más que el valor de cambio o de uso, ya que su leitmotiv es la maximización de la utilidad.

En la vida moderna y profundamente instrumental, cualquier cosa, objeto y acción es susceptible de ser empleada en función de su valor de cambio o uso. La racionalidad lúdica planteada por Suits trata de infiltrar un nuevo modo de enfocar y generar los planes de vida buena, a saber, aquella consistente en actividades intrínsecamente valiosas, no en la utilidad. En el seno de la filosofía continental, diversos filósofos han desarrollado intuiciones muy similares a las que Suits presenta en su The Grasshopper. Entre ellos, José Ortega y Gasset, quien en Prólogo a 'Veinte años de caza mayor', del Conde de Yebes presenta una visión de la caza como un juego 
deportivo que se asemeja mucho a la concepción de juego de Suits (Coni11 Sancho, 2016; Ilundáin Agurruza, 2016). Allí, afirma Ortega:

En la medida misma en que el arma iba siendo cada vez más eficaz, se fue el hombre imponiendo limitaciones frente al animal para dejar a este su juego, para no desnivelar excesivamente la pieza y el cazador, como si ultrapasar cierto límite en esa relación aniquilase el carácter esencial de la caza, transformada en pura matanza y destrucción. De aquí que el enfronte entre el hombre y el animal tenga una frontera precisa, en que la caza deja de ser caza; justamente allí donde el hombre da suelta a la inmensa superioridad técnica, esto es, racional, sobre la animálcula. El pescador que envenena el arroyo serrano para aniquilar fulminantemente, de un golpe, las truchas que en él se afanan, deja ipso facto de ser cazador (Ortega y Gasset, 1999: 38)

Más recientemente, Peter Sloterdijk, en su colección de ensayos sobre arte, titulada El imperativo estético, ha retomado esta cuestión para, del mismo modo que Suits y Ortega, utilizar el juego y su racionalidad antiinstrumental como crítica al pensar instrumentalista de la modernidad. Ante la razón instrumental, Sloterdijk opone la razón ascética. Esta oposición entre lo ascético y lo instrumental nos permite establecer otro paralelismo más entre Ortega y Sloterdijk, ya que este primero, tanto en La rebelión de las masas, como en su ensayo "El origen deportivo del estado", tematizó la conexión entre lo jovial y lo ascético en los orígenes del estado como formación política:

Conforme se avanza por la existencia, va uno hartándose de advertir que la mayor parte de los hombres -y de las mujeres- son incapaces de otro esfuerzo que el estrictamente impuesto como reacción a una necesidad externa. Por lo mismo, quedan más aislados y como monumentalizados en nuestra experiencia los poquísimos seres que hemos conocido capaces de un esfuerzo espontáneo y lujoso. Son los hombres selectos, los nobles, los únicos activos, y no solo reactivos, para quienes vivir es una perpetua tensión, un incesante entrenamiento. Entrenamiento = áskesis. Son los ascetas (Ortega y Gasset, 1964, capítulo vII).

Esta discusión acerca del jugar a juegos y su oposición a la racionalidad instrumental moderna, como decíamos, es retomada por Sloterdijk con el fin de enfrentarnos a los problemas que la racionalidad moderna instrumental ha generado y, a la vez, mostrar una posible vía de solución de estos a través tanto de la racionalidad ascética, como de la racionalidad lúdica. Los dos textos principales en que Sloterdijk explora ambos tipos de racionalidad son: «En favor de una filosofía del juego» $y$ «El ocioso regresa a casa: o el final de la coartada - y una teoría sobre el fin del arte» (Sloterdijk, 2017d). En lo que sigue, analizaremos ambos textos, con el fin de mostrar la propuesta de Sloterdijk en lo que respecta al juego y el modo de vida ascético. 


\section{SLOTERDIJK Y SU IMPERATIVO METANOÉTICO}

En otros trabajos (López Frías \& Gimeno, 2018), hemos expuesto detalladamente en qué consisten tanto el punto de partida ontológico de Sloterdijk, así como el ascetismo que define su propuesta filosófica. ${ }^{2}$ En el presente trabajo, resulta vital dar cuenta de dichas cuestiones, si bien lo haremos de un modo más somero. Los dos conceptos clave a explicar son: la circunstancia ontológica y el imperativo metanoético (Sloterdijk, 2009, 2013).

La circunstancia ontológica pone las bases de la propuesta de Sloterdijk, que se define en sus inicios por ir desde Heidegger, pero más allá de él. Empezando por el «ir desde», entendemos que Sloterdijk asume la propuesta ontológica que Heidegger expone en Ser $y$ tiempo. Es decir, Sloterdijk parte de la tesis y descripción fenomenológica heideggeriana en la que, por definición, el Dasein ${ }^{3}$ se define por ser el único ente capaz de interrogarse a sí mismo y por sí mismo; es decir, el único ente que es capaz de dar cuenta y preguntarse por su ser:

después de Heidegger se extiende un terreno-teoría que solo ha pisado quien -pensando con Heidegger contra Heidegger, para usar el giro, tan conocido como improductivo de un antiguo lector de Heidegger- se liberó de la hipnosis del maestro para, gracias sobre todo a sus energías, alcanzar una posición que, por todo lo que de él sabemos, le habría disgustado (Sloterdijk, 2011:5).

A la sazón, Heidegger define la esencialidad del ente como temporeidad o temporalidad. Esta viene definida como la asunción y toma de conciencia por parte del Dasein de su propia finitud: somos entes finitos que deben dar cuenta tanto de su finitud, como de su condición de arrojados-en-elmundo:

2 En otro trabajo (López Frías \& Gimeno, 2018), hemos expuesto algunas conclusiones preliminares sobre la relación que existe entre Heidegger y Sloterdijk. También hemos dado cuenta de algunas posiciones respecto a dicho tema, en especial, los trabajos en castellano de Adolfo Vásquez Rocca (2013a: 2017), así como el trabajo de Carla Cordura (2008), Heidegger y Sloterdijk. La recepción filosófica. Al igual que comentamos en aquel trabajo, la relación entre ambos filósofos se nos revela como un tema que consideramos tan complejo como absolutamente abierto a debate. Dado el asunto que aquí nos ocupa, así como el espacio limitado del que disponemos, dejamos para otra ocasión un trabajo centrado en dicha relación, con el firme propósito de generar una discusión que, a la sazón, se nos antoja primordial y profundamente relevante.

3 «El planteamiento de esta pregunta, como modo de ser de un ente, está, él mismo, determinado esencialmente por aquello por lo que en él se pregunta -por el ser-.A este ente que somos en cada caso nosotros mismos, y que, entre otras cosas, tiene esa posibilidad de ser que es el preguntar, lo designamos con el término Dasein» (Heidegger, 2012: 28). 
Solo un ente que es esencialmente venidero en su ser de tal manera que, siendo libre para su muerte y estrellándose contra ella pueda dejarse arrojar hacia atrás, hacia su "Ahí fáctico", es decir, solo un ente que como venidero sea cooriginariamente un ente que está siendo sido, puede, entregándose a sí mismo la posibilidad heredada, asumir la propia condición de arrojado y ser instantáneo para «su tiempo».Tan solo la temporeidad propia, que es a la vez finita, hace posible algo así como un destino, es decir, una historicidad propia (Heidegger, 2012:398).

En lo que respecta al «ir más allá de Heidegger», Sloterdijk (2011) considera que, si bien Heidegger define en gran medida la circunstancia ontológica del Dasein, olvida una segunda dimensión que sería tan importante como el tiempo, a saber: el espacio. Según Sloterdijk, en Ser y tiempo, el espacio es simplemente tematizado como mundo, pero no se profundiza en qué consiste ese espacio, ni cómo lo habitamos (o debemos habitar). Enfatizando el olvido del espacio por parte de Heidegger, Sloterdijk escribe una trilogía -Esferas- dedicada a definir lo que él entiende por espacios. Tanto es así, que Sloterdijk afirma que su trilogía debería denominarse Ser y espacio (Sloterdijk \& Klein, 2016: 141):

Dado que los seres humanos como tal son el efecto del espacio que han sido capaces de crear [...] Muestran que el desarrollo humano solo puede ser comprendido en relación a la construcción espacial secreta para la antropogénesis. Este monstruo de libro con sus dos mil quinientas páginas debería, de hecho, ser llamado Ser y espacio, en vez de Esferas. Pero los tiempos de trabajar en teoría ontológica se han acabado. Por lo tanto, me he decidido por algo más contemporáneo, por un tipo de teoría constructivista y antropológica.

Esferas, globos y espumas son, según Sloterdijk, los diferentes tipos de espacios ontológicos que, construidos por el hombre, le sirven para habitar el mundo; sobrevivir en él y desarrollar unos determinados planes de vida. Los espacios deben ser interpretados en clave de sistemas inmunológicos, es decir: espacios elaborados por el hombre, con el principal propósito de generar espacios y lugares habitables en los que poder coexistir.

En la esfera humana existen no menos de tres sistemas inmunitarios, los cuales trabajan superpuestos, con un fuerte ensamblaje cooperativo y una complementariedad funcional [...], un sistema de prácticas simbólicas, o bien psico-inmunológicas, con cuya ayuda los hombres logran, desde tiempos inmemoriales, sobrellevar más o menos bien su vulnerabilidad ante el destino, incluida la mortalidad, a base de antelaciones imaginarias y del uso de una serie de armas mentales (Sloterdijk, 2013:24).

De no existir espacios inmunológicos, la vida sería invivible dado que estaríamos arrojados al vacío o la nada. El mundo, por lo tanto, solo puede interpretarse en clave de espacios artificiales que posibilitan la existencia 
en un mundo que, sin ellos, sería caótico y atroz. Tal y como afirma Adolfo Vásquez Rocca, «el hombre no podría conservarse dentro de la naturaleza tal como esta es, de primera mano, sino que se ve abocado a emprender una modificación práctica de cualquier realidad natural con la que se encuentra» (Vásquez Rocca, 2013b: 332-333). En este sentido, para Sloterdijk, tiempo y espacio conforman lo que hemos denominado como circunstancia ontológica. El segundo paso en la propuesta de Sloterdijk es responder a la pregunta por el cómo deberíamos habitar los espacios. Es decir, cómo deberíamos comportarnos dentro de dichos espacios. Para ello, Sloterdijk recurre al imperativo metanoético de la ascesis.

\footnotetext{
En un mundo que pertenece a Dios, el ser humano hace de sí mismo demasiado con solo alzar la cabeza; en un mundo perteneciente a los hombres, estos hacen de sí mismos, por lo general, demasiado poco. Que la razón de la desigualdad entre los hombres pudiera residir en sus formas de ascesis -en la diferencia de postura en relación con los retos de una vida como ejercicio- es un pensamiento nunca anteriormente formulado en la historia de las investigaciones sobre las últimas causas de la diferencia existente entre los hombres (Sloterdijk, 2013: 58).
}

De entre los múltiples modos en que podemos dar respuesta a nuestra situación ontológica, Sloterdijk apuesta por aquella que consiste en una vida basada en una versión secularizada de la ascesis. Esta, tal y como muestra en Has de cambiar tu vida (2013), conduce a un tipo de vida definido por la lucha, el esfuerzo y el sacrificio. Actuar ascéticamente tiene que ver con la tarea laboriosa que implica habitar los espacios inmunológicos.Además, para Sloterdijk, la vida ascética es la vida auténtica, porque es la que mejor responde a la circunstancia moderna. En este sentido, cabe aclarar cómo Sloterdijk comprende dicha circunstancia.

\section{SLOTERDIJK: CRÍTICO DE LA MODERNIDAD}

Sloterdijk proporciona un análisis de la modernidad basado en dos pilares. Por un lado, esta se define por el pluralismo tanto de visiones comprehensivas del mundo, como de identidades que generan compartimentos estancos a los que Sloterdijk denomina «burbujas». Por otro lado, la modernidad está sustentada sobre lo que Sloterdijk denomina «actitud de endeudamiento» (Sloterdijk, 2017b). Las economías de los países desarrollados dependen del endeudamiento público; los individuos a título personal recurren constantemente al préstamo de dinero para satisfacer sus deseos más inmediatos; y, a escala más global, las sociedades modernas constante- 
mente "piden prestados» recursos al medio ambiente para continuar con su ritmo de producción y consumo. Si esto es así, entonces los espacios inmunológicos modernos se basan esencialmente en un modelo de racionalidad instrumental sostenido por una actitud de endeudamiento que hipoteca el futuro en pro del presente.

En resumen: según Sloterdijk, el tipo de vida moderna presenta dos grandes desafíos: la desconexión entre burbujas, entendidas como sistemas inmunológicos, y el constante estar en el alambre en lo que respecta al futuro de la humanidad. Ambos problemas se retroalimentan y no pueden ser concebidos por separado. En lo que sigue, para no confundir al lector, explicaremos el segundo de los desafíos para, más adelante, avanzar al primero y mostrar la conexión entre ambos.

Según Sloterdijk, de un modo nietzscheano, concibe la existencia moderna como la propia de un funambulista.$^{4} \mathrm{El}$ hacer del endeudamiento nuestro modo de ser nos obliga a vivir en equilibrio ante el temor constante de caer al vacío. Ante tal situación, afirma Sloterdijk, hasta el día de hoy, el ser humano moderno se ha dedicado a tratar de retrasar una caída que, a todas luces, parece irremediable. Es decir, ha puesto todo su esfuerzo en ralentizar la llegada de una catástrofe que sabe es inevitable, sin hacer nada para remediar su situación de riesgo. De hecho, afirma Sloterdijk, el problema del individuo moderno es que no puede hacer nada para remediar su situación, a no ser que renuncie a su propia identidad. Identidad marcada y definida por la actitud de endeudamiento que le conduce a consumir y producir sin freno.

Sloterdijk, por lo tanto, propone al ser humano moderno un cambio de identidad. Dicho cambio consiste, en primer lugar, en el imperativo de llevar un tipo de vida más sostenible, más ascética. Es decir, como reza el título de uno de sus libros, Sloterdijk da al hombre moderno el imperativo metanoético: «¡Has de cambiar tu vida!” [...] Es el imperativo absoluto, el mandamiento metanoético por antonomasia» (Sloterdijk, 2013: 43). Segun-

4 La expresión de funambulista empleada por Sloterdijk puede ser interpretada, tal y como ocurre con Nietzsche, como una distinción entre los dos modos de interpretar metanoéticamente la actitud del ser humano dentro de su circunstancia. Nos referimos al modo auténtico o «superhombre»e inauténtico o «animal». Es decir, la circunstancia que debe salvar el ser humano es, a la sazón, la de encontrarse en perpetuo equilibrio entre los extremos «Mas Zaratustra contempló al pueblo y se maravilló. Luego habló así: El hombre es una cuerda tendida entre el animal y el superhombre -una cuerda sobre un abismo-. Un peligroso pasar al otro lado, un peligroso caminar, un peligroso mirar atrás, un peligroso estremecerse y pararse. La grandeza del hombre está en ser un puente y no una meta: lo que en el hombre se puede amar es que es un tránsito y un ocaso.Yo amo a quienes no saben vivir de otro modo que hundiéndose en su ocaso, pues ellos son los que pasan al otro lado» (Nietzsche, 2003: 38). Para un análisis más en detalle de esta relación, véase Adolfo Vásquez Rocca (2010). 
do, dicho cambio en el modo de vida moderno exige una acción global, es decir, que los seres humanos nos demos cuenta de que nuestros problemas nos afectan a todos, precisamente porque todos somos no solo los causantes; además somos responsables de ellos. Así pues, el esfuerzo ha de realizarse, si pretende ser efectivo, de modo colectivo y global. El esfuerzo colectivo constituye el segundo de los aspectos del imperativo metanoético.

En nuestra situación ontológica acrobática, todos debemos exigirnos el estar a la altura de nuestro tiempo y circunstancias, con el firme propósito de encontrar una solución a lo que parece un destino irremediable, perverso y trágico. Según Sloterdijk, para ello, hace falta la venida de una Segunda Ecúmene, por la que los individuos volvamos a estar unidos bajo una misma narrativa social, política y metanoética capaz de reescribir el destino del mundo. En términos de Sloterdijk, hace falta la creación de un sistema inmunológico que dé acogida a toda la humanidad y que, además, le permita, como humanidad, dar respuesta a la situación en que se encuentra. El problema de esta propuesta es el siguiente: ¿cómo generar unidad en una época que ha hecho de la individualidad su identidad?

\section{JUEGO Y SLOTERDIJK: ¿UN MODO DE VIDA MÁS LÚDICO? ¿EN QUÉ SENTIDO?}

Con el fin de dar respuesta a la pregunta anterior, Sloterdijk pone su mirada en el juego y en el arte. ${ }^{5}$ Según él, estas actividades tienen el potencial de generar la mediación y unión necesarias para ayudar a los individuos modernos a cambiar tanto sus vidas, así como el destino del mundo. Para Sloterdijk, el juego posee el carácter revolucionario que hace falta para revertir nuestra situación y generar una sociedad distinta. Siguiendo con esta analogía, Sloterdijk toma la figura romántica del «ocioso» (también traducido por «tunante») de Joseph von Eichendorff ${ }^{6}$ como la personificación del carácter y potencial revolucionarios del juego.

5 Como es bien sabido, esta posición no es completamente novedosa. Desde Kant, el concepto de juego libre ha tenido un papel importante en la filosofía continental (Gutiérrez, 1999) hasta alcanzar su mayor popularidad en autores románticos como Fichte y Schelling, y siendo recuperado en la filosofía contemporánea por Gadamer, entre otros. En lo que respecta a la filosofía del deporte como disciplina, el análisis del concepto jugar se retrotrae a la recepción del Homo ludens del historiador Johan Huizinga. No obstante, tematizar estas cuestiones nos llevarían demasiado lejos de nuestro cometido en este texto. Se recomienda la lectura de las obras de Mihai I. Spariosu Dionysus Reborn (1989) y God of Many Names (1991).

6 Respecto al empleo del concepto de ocioso cabe explicar algunas cuestiones que resultan de vital importancia para el propósito de nuestro trabajo. En primer lugar, el término empleado por 


\subsection{El juego y la modernidad}

Primero, pensar el juego como entidad ontológica supone, según Sloterdijk, un poner en cuestión el pensamiento metafísico moderno. Desde el propio Platón, el esquema metafísico moderno se ha caracterizado por distinguir entre dos clases de fenómenos: permanentes y temporales; esenciales y contingentes; forma y materia; razón y sensaciones (Sloterdijk, 2017a). El juego, dentro de este esquema, es concebido como un fenómeno temporal, con caducidad y anclado en la naturaleza sensual de los individuos.

Frente a la seriedad de actividades de corte intelectual y productivas, el juego resulta un aspecto secundario que poco o nada importa en lo que respecta al existir humano. Es decir, el juego no es esencial para el desarrollo de las actividades necesarias para la existencia humana. Las actividades de corte lúdico no son más que un pasatiempo, un receso de nuestras actividades diarias básicas, que son aquellas que realmente importan. El desarrollo de la sociedad industrial y del consumo no hizo más que acrecentar la actitud negativa hacia el juego, ya que lo ocioso resulta contrario y peligroso para el orden productivo que sustenta dichas sociedades. En ellas, solo lo relativo al trabajo importa, el resto posee un valor secundario.

¡Arbeit macht frei! - «el trabajo libera»- frase que de modo perverso aparecía a las entradas de numerosos campos de concentración nazis. La idea de una racionalidad instrumental, productiva y moderna que únicamente asume como válida, la idea de que el hombre es un ser-para-el-traba-

Eichendorff en su obra Aus dem Laben eines taugenichts y traducida al castellano como: De la vida de un tunante es el de Taugenucht. El propio Germán Garrido encargado tanto de la edición como de la traducción de la obra de Eichendorff para Ediciones Cátedra comenta al respecto: «El protagonista pasa a ser a partir de entonces el Taugenichts (a pesar de que el término ya no vuelve a repetirse en el texto), denominación que posee un valor connotativo que ninguna traducción consigue rescatar. Taugenichts significa literalmente 'el que nada hace y en nada rinde', el ocioso. Aunque el término encierra una cierta carga negativa, no puede en modo alguno equipararse al de "ocioso" o al de "holgazán". El Taugenichts es quien ni encaja ni desea encajar en ninguna ocupación, el superfluo, y el término que más se le aproxima es de tunante, como supo ver con acierto Alfonso Gallart en la primera traducción del texto al español» (Eichendorff, 2008: 25) Nosotros, por cuestiones relacionadas con la facilitación de la comprensión de dicho término, hemos optado por emplear el de "ocioso». Consideramos que, tal y como parece desprenderse de las palabras de Germán García, podrían emplearse como sinónimos tanto tunante como ocioso. Aun así, apostar por el término tunante, en lo que se refiere a los objetivos del presente trabajo, creemos que resultaría ciertamente confuso y, a la sazón, poco práctico para referir ese tipo de racionalidad que hace referencia a la despreocupación respecto a los imperativos de una racionalidad opuesta, es decir, la racionalidad instrumental. Por lo tanto, cuando nos referimos a una «racionalidad ociosa» o al término «ocioso» será, siempre, con el sentido e intención que remite a ese cambio de paradigma racional de lo instrumental a lo "ocioso» o «tunante»; a un tipo de racionalidad que escapa por la brecha definitiva que ha terminado hundiendo al buque de la racionalidad instrumental. 
jo. Más allá del trabajo nos metemos en las áreas de lo irrelevante, lo superfluo y carente de una seriedad que se exige por imperativo productivo. La recuperación de la relevancia del juego en nuestra vida intelectual supone un intento de criticar e ir más allá de la metafísica occidental dominante.

Para Sloterdijk, el arte nos brinda el mejor ejemplo de cómo tratar de superar la distinción entre lo serio y lo no serio o, más bien, entre el trabajo y lo lúdico. ${ }^{7}$ El juego parte de la concepción del individuo como creador. Para poder jugar, el individuo ha de crear un espacio «artificial» donde la actividad lúdica pueda discurrir. Sin este ejercicio de creación, resultaría imposible para al individuo participar en dichas actividades. De un modo muy similar a Suits, Sloterdijk sigue a Egon Friedell para definir el juego como «una abundancia de problemas» (Sloterdijk, 2017a: 108). Para jugar, los individuos encauzan sus energías en la superación de problemas, unos problemas que, dado el carácter artificioso del mundo de juego, han de considerarse como artificiales o innecesarios.

En la tarea de superar dichos obstáculos, los individuos encauzan sus energías en el juego, quedan enganchados a él y convierten esta actividad en última, es decir, en la única actividad que importa en el momento del juego. Al depositar sus esfuerzos en la realidad del juego, las actividades consideradas como esenciales para el sistema productivo y de consumo a la base de nuestras sociedades, terminan pasando a un segundo plano. Lo cual revierte la lógica calculadora y productiva moderna. Además, afirma Sloterdijk, el juego se convierte en un lugar para el desarrollo personal y social:

En el juego puro, los factores serios de la vida no son contrapuestos a los del juego, sino una parte intrínseca de él; ellos lo mantienen en movimiento, le dan sustancia, contenido universal y humanidad (Sloterdijk, 2017a: 106).

Según Sloterdijk, el juego desafía la lógica de nuestras sociedades capitalistas y, también, de la razón instrumental que les proporciona sustento ontológico, pues nos sitúa en un ámbito en el que no todo se puede calcular o planear. La improvisación dentro del juego, así como la incertidumbre de su resolución, son elementos centrales del jugar. Las capacidades tanto de crear el espacio donde el juego es posible, como de navegar las dificultades que encontramos dentro de él, convierten al individuo en una fuente

7 Entre todas las actividades de corte lúdico, para Sloterdijk, el arte supone la forma más excelsa: «Los seres humanos, como autores de obras de arte, el tipo de arte más excelso, se reconcilian con lo innecesario de un modo ejemplar. En el arte, lo accidental es necesario para, por así decirlo, la salvación» (Sloterdijk, 2017a: 104). 
de vitalidad creativa e inventiva que busca una vida plena. El individuo entregado a lo lúdico vive la vida entregado a la «sobreabundancia» (Sloterdijk, 2017a: 108). Dicha vida «[t]iene algo de sobra, con lo que ella nos permite jugar; nos ofrece juegos y quiere otras vidas, nuevas vidas para unirse al juego en este mundo y en otros» (Sloterdijk, 2017a: 108).

Sloterdijk concibe el juego como fuente de vitalidad; de realización de posibilidades. En este sentido, resulta notable la relación entre la modernidad y el jugar. Por un lado, la modernidad parece aspirar al empoderamiento de los individuos para alcanzar una sociedad utópica y ociosa del postrabajo. En esta, los individuos se realizan a sí mismos de modo autónomo, decidiendo el tipo de vida que desean desarrollar, sin que un cierto modo de vida les sea impuesto, bien sea por necesidad natural u obligación social. Lo que pretende el individuo moderno, pues, es modificar el mundo y la necesidad de responder a sus desafíos naturales con el fin de llevar a cabo modos de vida más ociosos o auténticos. En un mundo ocioso, dónde la necesidad y el trabajo hayan sido eliminados, los individuos se embarcarían solo en aquellas actividades que tienen razones para valorar. Esto permitiría, según Sloterdijk, alcanzar la emancipación ya que los seres humanos podrían llegar a ser lo que realmente son. Por lo tanto, lo lúdico es concebido como «la habilidad humana de existir [; como] una cuestión de [...] creación autónoma» (Sloterdijk, 2017b: 288).

Por otro lado, la modernidad parece negar la posibilidad de alcanzar tal sociedad ociosa del postrabajo, pues hacerlo negaría una de las bases de la propia modernidad: la centralidad del trabajo y la producción. El objetivo de la modernidad es la constante creación de riqueza y progreso, pero sin saber para qué sirve dicha riqueza y progreso. De este modo, el sujeto moderno se embarca en una interminable búsqueda de riqueza; en la búsqueda de un futuro de constante crecimiento material del cual nunca será capaz de librarse, viviendo en un constante afán por producir, generar riqueza y satisfacer deseos que nunca acaban y que, por lo tanto, no podrán derivar en un tipo de sociedad del postrabajo:

el mejorar no reconoce el presente, la gente que vive en la manía de la transformación han perdido cualquier criterio para saber lo que significa haber hecho lo suficiente. Hemos olvidado que el propósito de toda acción es no tener que hacer nada más (Sloterdijk, 2017b: 294).

La obsesión con el crecimiento material ha hecho al ser humano moderno perder de vista el objetivo emancipatorio de la modernidad, el cual ha quedado oculto tras los mecanismos y agentes que rigen la producción. Por 
ello, Sloterdijk llama la atención del sujeto moderno para pedirle, ante todo, que reflexione, que medite sobre la naturaleza de la sociedad en que vive. Con el fin de impedir que la propia sociedad moderna no se niegue a sí misma la posibilidad de realizar su objetivo final, Sloterdijk propone preguntarse por el origen y sentido de la riqueza y abundancia presentes en nuestras sociedades modernas:

Pero, ¿en qué se basan las ideas de los agentes del mundo del trabajo y el armamento, sino en la otredad y superioridad de la superioridad de la seguridad y disfrute futuros? ¿No es todo agente del sistema y todo sistema de acción desesperadamente endeudados hoy en día con la esperanza de algo mejor? (Sloterdijk, 2017b: 294).

Para Sloterdijk, pues, la clave es, primero, recordar de dónde viene la riqueza y con qué fin. En segundo lugar, una vez realizadas tales reflexiones, deberíamos «dar inicio a juegos de gran escala como ocasión de cada reunión en que las gentes de nuestro tiempo se honran e interpretan a sí mismos» (Sloterdijk, 2017b: 108-109). Es decir, debemos aprovechar actos colectivos para promover el espíritu lúdico entre los seres humanos, recordándoles que el logro del mundo ocioso es la meta de las sociedades en que viven. En este sentido, Sloterdijk concibe el movimiento en favor de lo ocioso como el modo de «llevar a la modernidad más allá de sí misma» recurriendo a un elemento marginal dentro de la propia sociedad moderna.

Con el fin de cultivar el espíritu revolucionario y colectivo de cambio que demanda nuestro tiempo, Sloterdijk propone «acampar a las puertas de la modernidad» para desarrollar otro tipo de sociedades que permitan a los individuos desarrollarse de modo pleno sin estar al servicio del sistema del capital. Dichos grupos,

serán capaces de desarrollar estilos de vida sostenibles para las nuevas mayorías que pronto plantarán sus tiendas de campaña a las puertas del mundo tradicional del trabajo [...] fomentando un proceso de vida cultural fuera de lo establecido (Sloterdijk, 2017b: 290).

Acampar a las afueras del mundo del trabajo para desarrollar comunidades ascéticas es la propuesta metanoética de Sloterdijk. Si queremos estar a la altura de las circunstancias actuales, hemos de seguir esta propuesta. Solo aquellos que sigan este camino podrán llevar a cabo modos de vida auténticos; el resto seguirán sumidos y movidos por las ruedas del mundo de la producción y el crecimiento material. 


\subsection{E1 'ocioso' como héroe moral a la altura de nuestros tiempos}

Sloterdijk toma la figura del «ocioso» como el héroe moral del mundo del postrabajo, su ejemplo debe guiarnos a la hora de conducir nuestras vidas del modo correcto. Es decir, con el fin de llevar a cabo modos de vida alternativos que se sitúen fuera de los márgenes del mundo del trabajo, lo que permitirá a los individuos el verdadero desarrollo pleno.Así pues, afirma Sloterdijk, la clave para ponernos a la altura de nuestro tiempo es que «el ocioso vuelva a casa». Este es «el genio evasivo moderno»:

[...] porque emergió de las relaciones de producción como un sonámbulo; porque no realiza un trabajo asalariado ni crea plusvalía. Él está feliz porque todavía no tiene idea de que los que se quedaron en casa, profundamente descontentos, terminarían algún día reclamando incluso su talento para soñar como una fuerza de producción social (Sloterdijk, 2017b: 290).

Para Sloterdijk, la buena noticia es que el proceso de vuelta a la ciudad del ocioso ya ha comenzado. Este ya está volviendo a nuestras ciudades, y lo está haciendo, afortunadamente según Sloterdijk, para quedarse porque el cambio hacia una sociedad más ascética y lúdica ha comenzado:

Cuando el ocioso regresa a casa; cuando el hombre de la ausencia romántico repentinamente parece haber sido convencido; cuando los límites se difuminan entre el sueño y el tiempo productivo; cuando los antiguos soñadores se vuelven realistas y realistas discuten las variaciones del apocalipsis, entonces es hora de aceptar que esto es un signo no de un episodio arbitrario y transitorio en el torbellino cultural moderno, sino que se trata de un evento no concebido que se está gestando e intentando surgir como concepto [...] El ocioso parece ocupado, abriendo restaurantes vegetarianos, boutiques, hoteles, estudios y agencias de viajes; establece comunas rurales, tiendas de alimentos saludables, centros de meditación; está corrompiendo la lógica y la ética occidentales (Sloterdijk, 2017b: 292, 295).

Solo el ocioso es, según Sloterdijk, capaz de llevar a cabo un modo de vida auténtico. Este se toma en serio las demandas de nuestro mundo y, con ello, puede revertir la situación a partir del sacrificio y del cambio radical del modo de vida típicamente moderno. Al concebirse como aislado del mundo que quiere cambiar, el ocioso ofrece modos de vida alternativos al basado en la producción y el trabajo.A saber, aquellos centrados en prácticas de tipo reflexivo, meditado y sacrificadas. Es decir, prácticas ascéticas que dejan de lado la racionalidad moderna de producción y satisfacción de deseo para crear un mundo de practicantes ascéticos: 
Han creado, por así decirlo, una escuela de yoga occidental sensual e intelectual, una forma de esfuerzo simbólico [...] alterando la estética de la regulación y la libertad de expresión y entre la disciplina especializada y el juego relajado, han desarrollado el tipo de Tantrismo occidental más efectivo (Sloterdijk, 2017b: 297).

De este modo, al apelar al esfuerzo y al sentido de comunidad, el ocioso se ha dado cuenta de que los problemas que nos acechan hoy en día no se pueden solventar si no es de modo colectivo. Por ello, necesitamos un concepto para sincronizar toda la vida actual, lo cual significa un concepto de calidad de tiempo y sabor particular para el momento presente en el contexto de la historia universal.Todos constituimos una sociedad de riesgo como un colectivo de ciudadanos cosmopolitas que se apoyan mutuamente. Tal sincronización crea una nueva asincronía, especialmente, entre los seres humanos que aceptan las demandas de su tiempo y para aquellos que rechazan el principio de solidaridad con la humanidad (Sloterdijk, 2017b).

Así pues, Sloterdijk se presenta como un revolucionario de lo ocioso o revolucionario ocioso. Ocioso porque exige una reformulación no tanto de los mimbres ontológicos que determinan nuestra circunstancia, sino de los principios metanoéticos con los que habitar los espacios inmunológicos. Ser un ocioso en el contexto revolucionario al que se refiere Sloterdijk, obliga a apropiarse de una actitud ascética capaz de revertir la lógica de la época moderna. En esta tarea de revertir la lógica moderna, Sloterdijk defiende la necesidad de incluir lo lúdico. Así pues, lo lúdico no es una mera cuestión superflua, al margen de una vida laboriosa y productiva. Por el contrario, lo lúdico, considerado como ocioso en una sociedad centrada en la producción, pasa a constituir un nuevo modo de racionalidad que apuesta por desplazar el centro productivo sobre el que orbitan nuestras acciones y planes de vida buena, para generar epiciclos en torno a lo ocioso.

\section{CONCLUSIÓN: EL JUEGO COMO MODO DE EXISTENCIA.}

El presente artículo ha tratado de presentar la posibilidad de equilibrar los pesos de las diferentes racionalidades que sostienen el modo de habitar nuestra circunstancia ontológica. Con ello, hemos expuesto los tipos de racionalidades que pueden ayudar a compensar la dictadura de la racionalidad instrumental de nuestro tiempo. Para ofrecer una alternativa a dicha racionalidad hemos analizado las propuestas filosóficas defendidas por Suits y Sloterdijk respectivamente. A través de estos filósofos, hemos trata- 
do de mostrar que las racionalidades lúdica y ociosa propuestas por estos autores se enfrentan, directamente, con la autoridad de la razón instrumental.

Estas racionalidades, empleadas para formar y habitar los espacios inmunológicos en la base de la propuesta de Sloterdijk, deberían contribuir a asentar un profundo cambio de paradigma en lo referido al modo de habitar el mundo y el tiempo en el que vivimos, siguiendo el modelo de la figura romántica del «ocioso». Es decir, lo ocioso y lo lúdico deben promover un cambio tanto de los principios rectores de nuestros planes de vida buena, como del sentido de la propia facticidad. Con ello, deben introducir un nuevo modo de escribir el relato de nuestra existencia en común con los otros, sin la necesidad de asumir, sin más, el dominio de la imperante razón instrumental que aboga por la eficiencia y la productividad como los modos esenciales de liberar al ser humano y dar sentido su vida.

\section{BIBLIOGRAFÍA}

Aristóteles (2000). Ética nicomáquea; Ética eudemia. Madrid: Gredos.

Conill Sancho, Jesús (2016). Ratiovitalistic hermeneutics and sport in the perspective of Ortega y Gasset. Sport, Ethics and Philosophy, 10(4), 416-429. https://doi.org/10.1080/17511321.2016.1217258

Eichendorff, Joseph (2008). De la vida de un tunante. Madrid: Cátedra.

Gutiérrez, Edgardo (1999). Imaginación y autonomía estética en la Crítica del juicio de Kant. Revista de Filosofía, 22, 169-176.

Heidegger, Martin (2012). Ser y tiempo. Madrid:Trotta.

Ilundáin Agurruza, Jesús (2016). Sports and Disciplined Movement - Paths to Stimulating Strivings. Recerca: Revista de Pensament i Anàlisi, 18, 49-72.

López Frías, Francisco Javier (2017). A Kantian view of Suits' Utopia: "a kingdom of autotelically-motivated game players". Journal of the Philosophy of Sport, 44 (1), 138-151.

López Frías, Francisco Javier \& Gimeno, Xavier (2017). La utopía de la razón lúdica de Bernard Suits. Paideia: Revista de Filosofía y Didáctica Filosófica, 35(107), 421-430.

- (2018). Esferología hermenéutica del deporte. Sobre el impacto de la obra de Peter Sloterdijk en la filosofía del deporte. Thémata. Revista de Filosofía. [En prensa] 
Martínez, Margarita (2010). Sloterdijk y lo político. Buenos Aires: Prometeo Libros.

Morgan, William J. (2008). Some Further Words on Suits on Play.Journal of the Philosophy of Sport, 35(2), 120-141. https://doi.org/10.1080/00948 705.2008 .9714734

Nietzsche, Friedrich W. (2003). Así babló Zaratbustra: un libro para todos y para nadie. Madrid:Alianza Editorial.

Ortega y Gasset, José (1964). La rebelión de las masas, con un prólogo para franceses, un epílogo para ingleses, y un apéndice: Dinámica del tiempo. Madrid: Espasa-Calpe.

- (1999). Prólogo a 'Veinte años de caza mayor', del conde de Yebes. Cuenca: Servicio de Publicaciones de la Universidad de Castilla-La Mancha.

Sloterdijk, Peter (2009). Esferas I burbujas, microsferología. Madrid: Siruela.

- (2011). Sin salvación: tras las huellas de Heidegger, Madrid:Akal.

- (2013). Has de cambiar tu vida: sobre antropotécnica. (P. Madrigal, trad.). Valencia: Pre-Textos.

- (2017a). For a Philosophy of Play. The aestbetic imperative: writings on art (100-112). Malden, MA: Polity.

- (2017b). Good-For-Nothing Returns Home. Or The End of an Alibi - and a Theory of the End of Art. The aesthetic imperative: writings on art (100-112). Malden, MA: Polity.

- (2017c). Architects Do Nothing but "Inside Theory". Peter Sloterdijk in conversation with Sabine Kraft and Nikolaus Kuhnert. The aesthetic imperative: writings on art (141-173). Malden, MA: Polity.

- (2017d). The aesthetic imperative: writings on art. Malden, MA: Polity.

Sloterdijk, Peter \& Klein, Bernhard (2016). Selected exaggerations: conversations and interviews 1993-2012. Londres: John Wiley \& Sons.

Spariosu, Mihai I. (1989). Dionysus Reborn. Play and the aesthetic dimension in Modern philosophical and scientific discourse. Ítaca y Londres: Cornell University Press.

- (1991). God of Many Names. Play, poetry, and power in Hellenic thought from Homer to Aristotle. Durham y Londres: Duke University Press.

Suits, Bernard (1967). Is Life a Game We Are Playing? Ethics, 77(3), 209213.

- (1974). Aristotle on the Function of Man: Fallacies, Heresies and Other Entertainments. Canadian Journal of Pbilosopby, 4(1), 23-40. 
- (1984). Games and Utopia: Posthumous Reflections. Simulation \& Games, 15(1), 5-24. https://doi.org/10.1177/0037550084151002

- (1990). The grasshopper: games, life, and Utopia. Boston: D. R. Godine.

Vásquez Rocca, Adolfo (2008). Peter Sloterdijk; esferas, helada cósmica y políticas de climatización. Valencia: Institució Alfons el Magnànim.

- (2010). Nietzsche y Sloterdijk: Depauperación del nihilismo, posthumanismo y complejidad extrahumana. Nómadas. Revista de Crítica de Ciencias Sociales y Jurídicas, 25, 439-151.

- (2013a). Peter Sloterdijk: el animal acrobático, prácticas antropotécnicas y diseño de lo humano. Nómadas. Revista de Crítica de Ciencias Sociales y Jurídicas, 39, 281-305.

- (2013b). Peter Sloterdijk: Experimentos con uno mismo ensayos de intoxicación voluntaria y constitución psico-inmunitaria de la naturaleza humana. Revista de Antropología Experimental, 13, 323-340.

- (2017). Heidegger y Sloterdijk: La provocación de la técnica, el claroscuro de la verdad y la domesticación del ser (más allá de la matriz bucólica de la pastoral heideggeriana). Nómadas. Revista de Crítica de Ciencias Sociales y Jurídicas, 51, 239-271.

Wittgenstein, Ludwig (1988). Investigaciones filosóficas. (A. G. Suárez, trad.). Barcelona: Crítica. 